Int. J. Dev. Biol. 53: 1379-1384 (2009)

doi: $10.1387 /$ ijdb.072309rf

\title{
"Notch-Off": a perspective on the termination of Notch signalling
}

\author{
RITA FIOR and DOMINGOS HENRIQUE* \\ Instituto de Medicina Molecular, Faculdade de Medicina de Lisboa, Lisboa, Portugal
}

\begin{abstract}
During Notch mediated lateral inhibition, interacting cells establish or amplify differences in Notch signalling, which are then translated into distinct cell fate decisions according to the developmental context. In recent years, several mechanisms that increase the signalling capacity of interacting cells have been uncovered (reviewed in Bray, 2006, Le Borgne, 2006, Schweisguth, 2004). However, mechanisms specifically targeted to downregulate receptor activity are also at work during lateral inhibition, contributing decisively to generate definitive differences between interacting cells. In this review, we discuss some of these mechanisms and their relevance for the overall architecture of the Notch pathway. We further highlight the importance of properly terminating Notch activity during cell fate decisions mediated by this pathway.
\end{abstract}

KEY WORDS: Notch signaling, neurogenesis, transcriptional regulation, robustness, hes gene

Cell-cell communication mediated by the Notch receptor is essential for the correct generation and patterning of most animal tissues. The initial characterization of Notch mutants in Drosophila, by Donald Poulson (Poulson, 1937, Poulson, 1945), led to the finding that absence of Notch activity in the embryo causes hyperplasia of the neural tissue at the expense of epidermis, a phenotype that was named "neurogenic" and later shown to be characteristic of several other Drosophila mutants (Lehmann et al., 1983, Poulson, 1937, Poulson, 1945). This led to a genetic definition of the Drosophila Notch pathway as a cascade of interacting neurogenic genes that function to control the formation of the fly nervous system (Vässin et al., 1985). However, Poulson also noted that Notch mutants have several other defects in embryonic and adult tissues, indicating that the pathway is involved not only in the development of the nervous system but also in most cell fate decisions that occur in the developing animal. Today, it is known that this pleiotropic function of the Notch pathway applies not only to Drosophilabut to all metazoa, where it regulates a myriad of cell fate decisions, affecting almost all animal tissues (reviewed in Artavanis-Tsakonas et al., 1999).

Notch-mediated cell communication seems to operate in two main ways: lateral inhibition and lateral induction. In the first case, Notch signalling mediates binary cell fate decisions and generates fine-grained patterns of cellular differentiation, while in the second case the Notch pathway is used to coordinate interactions between groups of cells and usually results in the establishment of boundaries separating different cellular fields. Although these two distinct operations rely on the existence of a few dedicated components, there is a number of core players that participate in both processes. These include the transmembrane Notch receptor and the interacting transmembrane ligands, both characterized by the presence of several EGF-like repeats in their extracellular domains. Notch is a large type-I transmembrane receptor that accumulates at the plasma membrane as a heterodimer, composed of the extracellular domain (NECD) and a membrane bound intracellular domain. These two polypeptides are formed in the trans-golgi as the result of proteolytic activity by a Furin protease that constitutively cleaves Notch molecules at the S1 site (Logeat et al., 1998) (Fig. 1). The Notch receptor heterodimer is then formed through a non-covalent $\mathrm{Ca}^{2+}$ dependent ligation and inserted at the plasma membrane. In Drosophila, however, it seems that the Notch transmembrane receptor is not a heterodimer as in vertebrates, being instead composed of just one single polypeptide (Kidd and Lieber, 2002).

The best characterized Notch ligands belong to the DSL family (Delta- Serrate-Lag2) and are also type-I transmembrane pro-

\footnotetext{
Abbreviations used in this paper: CSL, CBF-1, Drosophila Supressor of Hairless and C. elegans Lag-1 transcription factor; DSL, delta-serrate-lag2; LGD, lethal giant disc; MAM, mastermind co-activator, NECD, notch extracellular domain; NICD, notch intracellular domain; RIP, regulated intramembrane proteolysis.
}

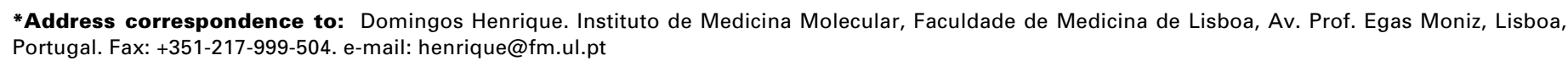

Final author-corrected PDF published online: 12 May 2008.

ISSN: Online 1696-3547, Print 0214-6282

(C) 2008 UBC Press

Printed in Spain 

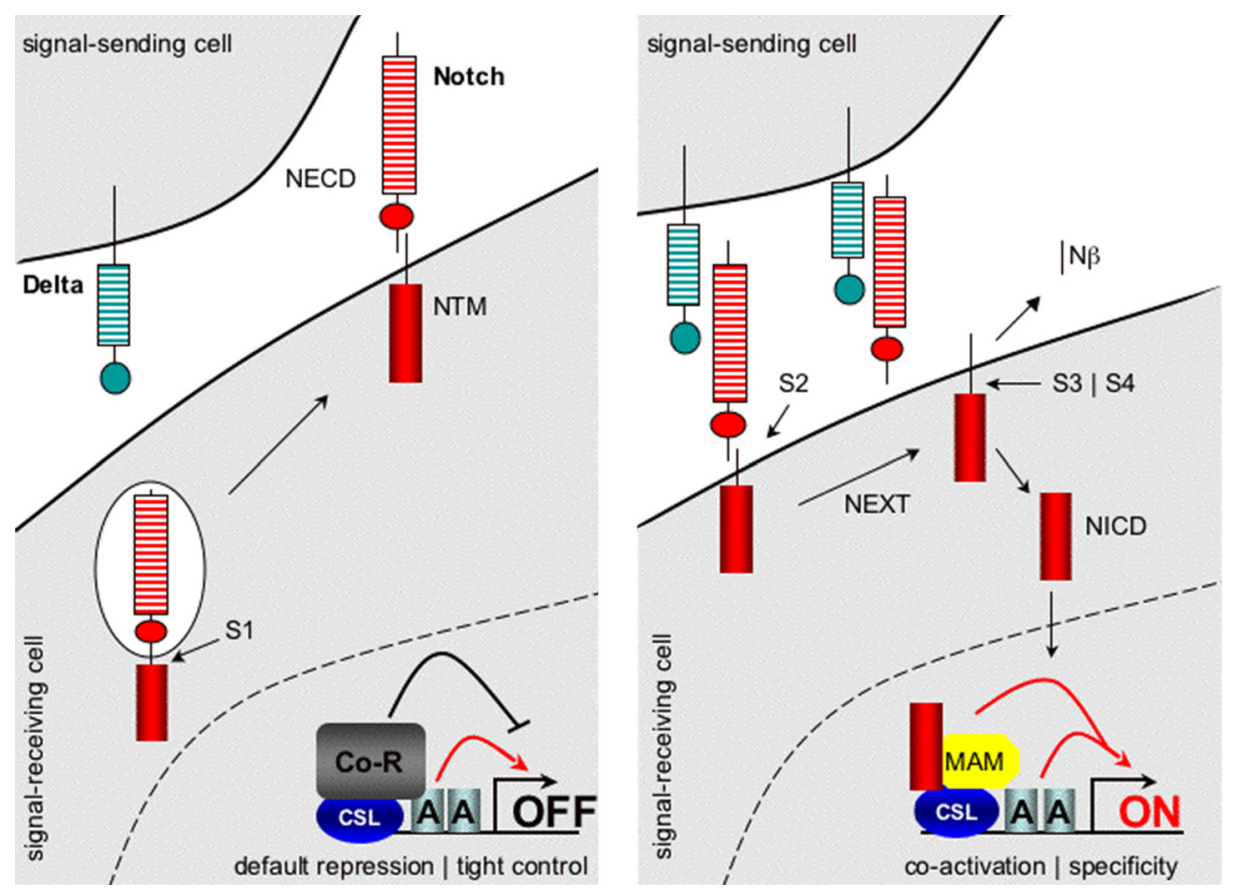

Although this core pathway is evolutionary conserved in the metazoan phyla, the number of paralogues for each element differs in various animal models. For instance, whereas Drosophila has only one Notchgene, mice have four different genes encoding Notch receptors (see Table 1). Even between vertebrates, the variation on the number of genes encoding core components of the Notch pathway is noteworthy, as for instance the different number of Delta and Notch genes in birds and mammals. Despite this variability in molecular components, the Notch pathway has essential and conserved roles in several developmental processes that are common to all vertebrates, like neurogenesis and somitogenesis (reviewed in Louvi and ArtavanisTsakonas, 2006, Pourquie, 2003).

The Notch mediated lateral inhibition (LI) mechanism regulates interactions between cells with equivalent potential, ensuring that they acquire one of two alternative fates. In this process, Notch signalling has no instructive role on the decision, functioning mainly to guarantee that the interacting cells follow alternative fates and, simultaneously, that both fates are in the end adopted. This involves a competitive Fig. A partial view of Notch in action, mediating communication between two adjace cells. The mechanisms that lead to Notch activity in the receiving cell are depicted, including the cleavage of Notch at the cell membrane and the assembly of a tripartite nuclear complex with the transcription factors CSL (CBF-1, Drosophila Supressor of Hairless and C. elegans Lag-1) and MAM (mastermind co-activator).

teins, although with much smaller and less conserved intracellular domains than Notch. Upon ligand-receptor interaction, the Notch receptor undergoes successive proteolytic cleavages that lead to the release of its intracellular domain (NICD) (reviewed in Schweisguth, 2004), which translocates to the nucleus (Fig.1). Here, NICD binds to the CSL transcription factor (an acronym for the mammalian $\underline{\mathrm{CBF}}-1$, Drosophila Supressor of Hairless and $C$. elegans Lag-1) and to the Mastermind co-activator (MAM), forming a ternary complex (Fig.1). This complex then recruits other factors, like the histone acetylase p300, the co-regulator SKIP (Ski-interacting protein) and the CDK8-Mediator complex, to activate transcription of target genes (reviewed in Barrick and Kopan, 2006).

In the absence of nuclear NICD, a repressor complex is instead assembled around the DNA-bound CSL protein, resulting in transcriptional repression of Notch target genes. Following ligandtriggered Notch activation and nuclear translocation of NICD, the interaction with CSL triggers a structural conformation that leads to the displacement of CSL-bound co-repressors and recruitment of MAM and other co-factors, forming a different transcriptional complex with activator properties. Thus, the Notch target genes which were previously repressed now become transcriptionally active.

There are many putative binding sites for the CSL transcription factor throughout the genome (Rebeiz et al., 2002), but the best characterized Notch targets are genes of the hes (hairy and Enhancer of split) and hrt (hairy-related) families, encoding bHLH (basic Helix-Loop-Helix) transcriptional repressors (reviewed in Davis and Turner, 2001), which function as effectors to implement the cell fate decisions mediated by Notch signalling. process whereby interacting cells compete not only by sending as much signal as possible, but also by preventing signal reception. So, any mechanism that leads the competing cells to produce more signal and/or to receive less signal might contribute to generate the normal outcome of LI: a "winner" cell with little receptor activity and strong signalling capacity, versus the "loser" cells that can only receive signal and activate the Notch cascade, being unable to signal back.

What is unique about the Notch pathway is its capacity to generate this stable outcome in so many different cell fate decisions. This "robustness" (Meir et al., 2002) arises from the unique architecture of the underlying genetic network, where an inter-cellular feedback loop plays a central role in connecting signal reception in one cell with the capacity to produce and send signal to neighbouring cells. In other words, when cells exchange signals during $\mathrm{LI}$, the more signal a cell receives, the less signal it is able to produce, so that any small difference in Notch activity between interacting cells is amplified and leads invariably to a distinct outcome in each of them: one cell becomes a signalling cell whereas the others become net receivers (reviewed in Greenwald and Rubin, 1992, Lewis, 1996). The starting point in these cellular interactions may be random, in case of stochastic decisions where any cell can become a signalling cell, or may be biased, in which case the inter-cellular feedback loop serves to reinforce an initial bias on signal directionality.

In recent years, various mechanisms have been uncovered that modulate the activity of the Notch pathway, from transcription to the intra-cellular trafficking of receptor and ligands, with an emphasis on the mechanisms that promote signal generation and receptor activation in interacting cells (reviewed in Bray, 2006, 
Schweisguth, 2004). However, how positive and negative mechanisms are integrated to regulate the temporal, spatial and directional aspects of LI-mediated cell interactions is still not completely understood. Here, we focus our attention on the mechanisms that negatively regulate Notch activity, discussing their importance for the functional architecture of the Notch pathway.

\section{Notch signalling: from the cell surface to the nucleus}

During Notch signalling, NICD release to the nucleus involves a two-step regulated intramembrane proteolysis (RIP) of the receptor, triggered by ligand binding. The Notch receptor can thus be viewed as a membrane bound transcription co-factor that integrates signalling events at the membrane and transduces directly to the nucleus, without any second messengers. Since RIP cleavage removes the receptor from the cell's membrane, each Notch molecule can transduce signal only once, implying that the regulation of the number and availability of Notch receptors at the cell surface must be critical to modulate signal strength. In addition, as the pathway does not rely on second messengers, no signal amplification is possible and signalling capacity must thus be highly dependent on the nuclear concentration of NICD, providing another nodal point for regulating the intensity and duration of Notch signalling.

\section{Regulation of Notch availability at the cell surface}

In recent years, it has become clear that endocytosis and intracellular trafficking of Notch receptors play a major role in signal modulation, controlling not only the availability but also the "quality" of receptors and ligands. For example, the enzyme O-fucosyl transferase (O-Fut) initiates a glycosylation cascade that is needed to generate a functional Notch receptor (Okajima and Irvine, 2002, Sasamura et al., 2003, Shi and Stanley, 2003), contributing also to promote the folding and exit of receptors from the endoplasmic reticulum (Okajima et al., 2005). In addition, O-Fut may control the removal of Notch molecules from the plasma membrane and their entry into the degradation compartment, thereby preventing an excessive accumulation of free receptors at the cell membrane (Sasamura et al., 2007).

Other mechanisms are known that regulate the presence of Notch receptors at the cell surface, involving the activity of various HECT domain E3 ubiquitin-ligases, like those belonging to the Nedd4 family (Drosophila Nedd4 and Supressor of Deltex, and mammalian Itch). These E3-ligases target Notch molecules to late endosomes and subsequent degradation by the lysosome (reviewed in Le Borgne, 2006). In contrast, another E3 ubiquitin-ligase, Deltex, is a positive regulator of Notch activity in Drosophila (Hori et al., 2004, Matsuno et al., 1995), although in mammalian cells it may also act to antagonize Notch (Izon et al., 2002). Altogether, the outcome of these ubiquitin modifications of the Notch receptor controls its availability at the cell surface and, thereby, the strength and duration of the signal.

There are still other mechanisms, not mediated by ubiquitylation, that also control endosomal sorting of the receptor and promote its targeting to lysosomal degradation. These involve the activity of the ESCRT complex (Moberg et al., 2005,
Thompson etal., 2005, Vaccari and Bilder, 2005) and of a newly identified protein - Lethal Giant Discs (LGD), that play important roles in restricting Notch signalling (Childress et al., 2006, Jaekel and Klein, 2006, Klein, 2003).

Numb is a membrane associated protein that also antagonizes Notch signalling in the Drosophila nervous system, by downregulating the activity of a positive regulator of Notch, Sanpodo. Numb is an endocytic regulator and triggers the alpha-adaptin mediated endocytosis of Sanpodo, targeting it to late endosomes, thereby inhibiting its positive interaction with Notch at the membrane (Hutterer and Knoblich, 2005). In vertebrates, however, the role of Numb in regulating Notch activity is still controversial. Although some studies point to Numb as a negative regulator that targets vertebrate Notch receptors for endocytosis and subsequent degradation (McGill and McGlade, 2003), the analysis of mutant mice without Numb activity during neurogenesis is difficult to reconcile with this view of Numb as antagonist of Notch signalling (Kuo et al., 2006, Li et al., 2003, Petersen et al., 2002, Zhong et al., 2000).

Another mechanism to prevent activation of the Notch pathway might involve a postulated dominant-activity of Delta ligands, which could bind Notch receptors in cis (within the same cell) and prevent their interaction with ligands from neighbouring cells (in trans). These cis-interactions are supposed to be nonactivating and result in down-regulation of Notch signalling in cells with high levels of Delta ligands. This mechanism has been suggested from the analysis of mosaic mutants in Droso phila (Heitzler and Simpson, 1993), but it has been difficult to gather biochemical data to support it. Still, it makes sense that during LI the winning cells use their excess of ligand not only to signal neighbouring cells but also to avoid Notch activation, by reducing the availability of the receptors at their cell membrane.

In other situations, removal of Notch receptors from the membrane is a pre-requisite to increase the signalling capacity of the cell, avoiding the occurrence of cis-interactions between ligands and receptors that might sequester ligand activity. This has been described during vulva formation in C.elegans, where Lin-3/EGF-Ras-MAPK signalling is known to induce Lin-12/ Notch removal from the membrane of the "winner" cell (P6.p) (Shaye and Greenwald, 2002). Actually, the signalling capacity of P6.p is severely decreased in mutants that fail to remove Lin12 /Notch from the membrane, and no LI occurs to sort out vulva

\section{TABLE 1}

\section{COMPONENTS OF THE NOTCH SIGNALLING PATHWAY ARE} EVOLUTIONARILY CONSERVED

\begin{tabular}{|c|c|c|c|c|}
\hline & Drosophila & C. elegans & Chick & Mammals \\
\hline Notch Receptor & Notch & $\begin{array}{l}\operatorname{lin}-12 \\
\text { glp-1 }\end{array}$ & $\begin{array}{l}\text { Notch1 } \\
\text { Notch2 }\end{array}$ & $\begin{array}{l}\text { Notch1 } \\
\text { Notch2 } \\
\text { Notch3 } \\
\text { Notch4 }\end{array}$ \\
\hline LIGAND & $\begin{array}{l}\text { Delta } \\
\text { Serrate }\end{array}$ & $\begin{array}{l}\text { lag-2 } \\
\text { apx-1 } \\
\text { arg-2 } \\
\text { f16b12.2 }\end{array}$ & $\begin{array}{l}\text { Delta1 } \\
\text { Delta4 } \\
\text { Jagged1 } \\
\text { Jagged2 }\end{array}$ & $\begin{array}{l}\text { Dll-1 } \\
\text { DIl-3 } \\
\text { DIl-4 } \\
\text { Jagged1 } \\
\text { Jagged2 }\end{array}$ \\
\hline CSL & $S u(H)$ & Lag-1 & CBF1/RBPJK & CBF1/RBPJK \\
\hline MAM & Mam & Lag-3 & $\begin{array}{l}\text { Mam1 } \\
\text { Mam2 } \\
\text { Mam3 }\end{array}$ & $\begin{array}{l}\text { Mam1 } \\
\text { Mam2 } \\
\text { Mam3 }\end{array}$ \\
\hline
\end{tabular}


fates (Shaye and Greenwald, 2005). Since this phenotype is dependent on the presence of the Lin-12/Notch extracellular domain, it has been suggested that an excess of receptor at the surface of mutant cells might sequester DSL ligands in cis and prevent their activity, thus blocking lateral inhibition of neighbouring cells (Shaye and Greenwald, 2005).

\section{Notch in the nucleus: stability and degradation}

Following Notch activation and NICD translocation to the nucleus, a tripartite complex is assembled around the DNAbound CSL transcription factor, leading to the expression of Notch target genes. The MAM co-factor is essential to organize this activator complex, recruiting other proteins that contribute to the transcriptional up-regulation of target genes. However, MAM also recruits the complex of cyclin $C$ and cyclin-dependent kinase 8 (CycC:CDK8), which directly phosphorylates NICD and targets it to proteosome degradation, after ubiquitylation by the Fbw7/Sel10 ubiquitin ligase (Fryer et al., 2002, Fryer et al., 2004). Thus, MAM acts like a "kamikaze" cofactor that when recruited to the transcription complex brings also the means to swiftly terminate its activity, allowing a tight control of the level and timing of Notch signalling.

The C-terminal PEST domain of NICD is directly involved in these phophorylation events, with three Serine residues known to be phosphorylated by the CycC:CDK8 kinase (Fryer et al., 2004). However, another region of the PEST domain has been shown to be involved in NICD turnover, containing a string of four Ser residues (WSSSSP) that were not identified as CycC:CDK8 targets. Deletion of this small region in the Notch molecule leads to NICD hypophosphorylation, decreased turnover and stabilization of the CSL/NICD/MAM complex, with a consequent increase in Notch signalling (Chiang et al., 2006). These deletions result in strong "gain-of-function" phenotypes and can be detected in T-cell acute lymphoblastic leukemia ( $\mathrm{T}$ ALL), a tumor derived from T-cell progenitors which correlates with uncontrolled Notch activity (Chiang et al., 2006, Weng et al., 2004).

NICD can be also phosphorylated by another kinase - GSK$3 \beta$ (Espinosa et al., 2003, Foltz et al., 2002), although this does not seem to happen when NICD is present in the DNA-bound complex with CSL and MAM (Fryer et al., 2004). Also, the outcome of this phosphorylation is not yet clear, as it can lead to higher or lower NICD activity depending on the cellular context (Espinosa et al., 2003, Foltz et al., 2002).

\section{Target genes and termination of Notch signalling}

Although NICD is a short-lived transcription co-factor, it is possible that its target genes encode stable transcription factors that generate a sustained activity of the pathway. This seems unlikely, as the main Notch effectors, belonging to the HES family of bHLH transcriptional repressors, are also subjected to a tight temporal regulation of their activity (reviewed in Kageyama et al., 2007b). Actually, not only HES proteins are short-lived (Hirata et al., 2004) but they are also able to repress transcription of their own genes, thereby ensuring that their activity is limited in time (Cooper et al., 2000, Fior and Henrique, 2005, Gajewski et al., 2003, Hirata et al., 2004). Furthermore, some HES proteins have been reported to be phosphorylated, leading to a decrease in their capacity to bind DNA and repress transcription (Strom et al., 1997), revealing that post-translational mechanisms at the level of Notch effectors might also contribute to restrict the duration of Notch signalling.

\section{The importance of a clean termination}

The described mechanisms to down-regulate Notch activity are important components of the LI intercellular feedback loop that amplifies differences between interacting cells. Their relative contribution may vary in different developmental contexts but, together with the mechanisms that positively regulate Notch signalling, they end up imposing a bias on the directionality of signal transduction, an essential feature of LI-mediated cell-cell interactions.

Actually, to achieve signal directionality in a competitive mechanism like LI, it is important not only to generate an excess of signalling activity delivered by "winner" cells but also to maximize reception of the signal in "loser" cells. Thus, it might seem paradoxical that $\mathrm{LI}$ is able to operate efficiently at limiting concentrations of Notch receptors at the cell surface and of NICD in the nucleus, as discussed above. However, this paradox is misguided and we would argue instead that this is a key feature of the LI mechanism, required to achieve an effective amplification of small fluctuations in Notch activity and establish clear differences between cells with equivalent potential. This applies, for instance, to the rapid turnover of NICD, which is needed to prevent its accumulation in the nucleus to levels that would otherwise buffer the system against small fluctuations and block the emergence of "winners" and "losers".

Another important consequence of the rapid NICD turnover in the nucleus is that it prevents NICD from being reused for target gene transcription, thereby producing bursts of Notch activity, instead of a sustained and prolonged activation. In addition, the negative auto-regulation of the target/effector hes genes, together with the short-lived nature of hes mRNAs and HES proteins, contribute also to this very transient character of the Notch response.

In summary, the Notch pathway's architecture is designed to produce an effective but highly transient response in interacting cells, with various mechanisms that negatively regulate Notch signalling contributing to this end. A recurrent theme in these mechanisms is that the players which drive the activity of the pathway are also instrumental in subsequent steps to restrict such activity. This is true, for instance, for the O-Fut protein, which is essential to generate an active Notch receptor but triggers also other modifications that restrict the receptor's capacity to interact with specific DSL ligands. Another striking example is the MAM co-factor, which is absolutely required to assemble a transcriptionally active complex at Notch target genes but recruits also the CycC:CDK8 kinase to trigger NICD proteosomal degradation.

This particular architecture of the Notch pathway allows a precise control of the amount of signalling experienced by interacting cells and is fundamental for the functioning of the intercellular feedback loop that amplifies signalling differences during LI. In addition, the capacity to effectively terminate Notch signalling by modifying or eliminating some of its components is important for the events that follow LI. Cells where Notch activity reached a 
peak can quickly terminate it, reset their potential and enter a new round of $\mathrm{LI}$, involving the same or a different set of alternative fates. This enables $\mathrm{LI}$ to regulate various histogenic processes where a pool of progenitors is maintained during an extended period of time, while giving rise to cells with specific and diverse fates. A good example of this happens during Drosophila and vertebrate neurogenesis, where neural progenitors (neuroblasts in Drosophila and neuroepithelial progenitors in vertebrates) can participate in several rounds of Notch-mediated decisions, resetting their levels of Notch activity after each round. If these cells are simultaneously able to "retune" their potential, by intrinsic or extrinsic mechanisms, the capacity to generate consecutive rounds of Notch-mediated LI can produce an additional outcome: the acquisition of different neural fates along the period of neurogenesis, i.e., neuronal diversity.

Another developmental process where progenitors go through several rounds of Notch activity occurs during vertebrate somitogenesis. Here, cells in the presomitic mesoderm (PSM) experience synchronized oscillations in Notch activity, a finding first revealed by the cyclic expression of hes genes in these cells (Palmeirim et al., 1997). More recently, using fluorescent reporters for Notch activity, these cycles have been visualized in vivoby time-lapse imaging of the developing presomitic mesoderm (Masamizu et al., 2006). Analysis of the network's architecture underlying these cycles of Notch signalling confirm the key role played by the mechanisms that terminate Notch activity (reviewed in Kageyama et al., 2007a, Pourquie, 2003), with a major contribution arising from the mechanism that controls the half-life of hes mRNAs and proteins (Hirata et al., 2004, Lewis, 2003).

\section{Final remarks}

In recent years, several mechanisms that positively regulate Notch signalling have been described, involving processes like transcriptional up-regulation of DSL ligands, their selective recycling to the cell membrane, and post-translational modifications of ligands and receptors to increase their mutual affinity (reviewed in Bray, 2006, Le Borgne, 2006, Schweisguth, 2004). However, in a competitive mechanism like $\mathrm{LI}$, the final outcome is dictated by the balance of positive and negative mechanisms, regulated globally in the ensemble of interacting cells through a unique intercellular feedback loop. Here, we discussed some of the mechanisms which are known to negatively regulate Notch signalling, at different steps of the pathway. We propose that these mechanisms are crucial to regulate timing and duration of Notch activity during $\mathrm{LI}$, underlying the generation of signalling directionality during cell interactions. We further propose that switching-off Notch activity after signalling has occurred is a critical aspect of the Notch pathway architecture that allows it to regulate progenitor maintenance and cell type diversification in several histogenic processes.

\section{Acknowledgments \\ We are grateful to all UBD members for help, support and positive discussions, and to Kate Storey for critical reading of the manuscript.}

\section{References}

ARTAVANIS-TSAKONAS, S., RAND, M.D. and LAKE, R.J. (1999). Notch signal- ing: cell fate control and signal integration in development. Science 284: 7706.

BARRICK, D. and KOPAN, R. (2006). The Notch transcription activation complex makes its move. Cel/124: 883-5.

BRAY, S.J. (2006). Notch signalling: a simple pathway becomes complex. Nat Rev Mol Cell Biol7: 678-89.

CHIANG, M.Y., XU, M.L., HISTEN, G., SHESTOVA, O., ROY, M., NAM, Y., BLACKLOW, S.C., SACKS, D.B., PEAR, W.S. and ASTER, J.C. (2006). Identification of a conserved negative regulatory sequence that influences the leukemogenic activity of NOTCH1. Mol Cel/ Bio/26: 6261-71.

CHILDRESS, J.L., ACAR, M., TAO, C. and HALDER, G. (2006). Lethal giant discs, a novel C2-domain protein, restricts notch activation during endocytosis. Curr Biol16: 2228-33.

COOPER, M.T., TYLER, D.M., FURRIOLS, M., CHALKIADAKI, A., DELIDAKIS, C. and BRAY, S. (2000). Spatially Restricted Factors Cooperate with Notch in the Regulation of Enhancer of split Genes. Dev Bio/221: 390-403.

DAVIS, R.L. and TURNER, D.L. (2001). Vertebrate hairy and Enhancer of split related proteins: transcriptional repressors regulating cellular differentiation and embryonic patterning. Oncogene 20: 8342-57.

ESPINOSA, L., INGLES-ESTEVE, J., AGUILERA, C. and BIGAS, A. (2003) Phosphorylation by glycogen synthase kinase-3 beta down-regulates Notch activity, a link for Notch and Wnt pathways. J Biol Chem 278: 32227-35.

FIOR, R. and HENRIQUE, D. (2005). A novel hes5/hes6 circuitry of negative regulation controls Notch activity during neurogenesis. Dev Bio/281: 318-33.

FOLTZ, D.R., SANTIAGO, M.C., BERECHID, B.E. and NYE, J.S. (2002). Glycogen synthase kinase-3beta modulates notch signaling and stability. Curr Biol 12: 1006-11.

FRYER, C.J., LAMAR, E., TURBACHOVA, I., KINTNER, C. and JONES, K.A. (2002). Mastermind mediates chromatin-specific transcription and turnover of the Notch enhancer complex. Genes Dev 16: 1397-411.

FRYER, C.J., WHITE, J.B. and JONES, K.A. (2004). Mastermind recruits CycC:CDK8 to phosphorylate the Notch ICD and coordinate activation with turnover. Mo/ Cel/ 16: 509-20.

GAJEWSKI, M., SIEGER, D., ALT, B., LEVE, C., HANS, S., WOLFF, C., ROHR, K.B. and TAUTZ, D. (2003). Anterior and posterior waves of cyclic her1 gene expression are differentially regulated in the presomitic mesoderm of zebrafish. Development 130: 4269-78.

GREENWALD, I. and RUBIN, G.M. (1992). Making a difference: the role of cell-cell interactions in establishing separate identities for equivalent cells. Ce//68:271 81.

HEITZLER, P. and SIMPSON, P. (1993). Altered epidermal growth factor-like sequences provide evidence for a role of Notch as a receptor in cell fate decisions. Development 117: 1113-23.

HIRATA, H., BESSHO, Y., KOKUBU, H., MASAMIZU, Y., YAMADA, S., LEWIS, J. and KAGEYAMA, R. (2004). Instability of Hes7 protein is crucial for the somite segmentation clock. Nat Genet 36: 750-4.

HORI, K., FOSTIER, M., ITO, M., FUWA, T.J., GO, M.J., OKANO, H., BARON, M. and MATSUNO, K. (2004). Drosophila deltex mediates suppressor of Hairlessindependent and late-endosomal activation of Notch signaling. Development 131: 5527-37.

HUTTERER, A. and KNOBLICH, J.A. (2005). Numb and alpha-Adaptin regulate Sanpodo endocytosis to specify cell fate in Drosophila external sensory organs. EMBO Rep 6: 836-42.

IZON, D.J., ASTER, J.C., HE, Y., WENG, A., KARNELL, F.G., PATRIUB, V., XU, L., BAKKOUR, S., RODRIGUEZ, C., ALLMAN, D. et al. (2002). Deltex1 redirects lymphoid progenitors to the $B$ cell lineage by antagonizing Notch1. Immunity 16: 231-43.

JAEKEL, R. and KLEIN, T. (2006). The Drosophila Notch inhibitor and tumor suppressor gene lethal (2) giant discs encodes a conserved regulator of endosomal trafficking. Dev Cel/11: 655-69.

KAGEYAMA, R., MASAMIZU, Y. and NIWA, Y. (2007a). Oscillator mechanism of notch pathway in the segmentation clock. Dev Dyn.

KAGEYAMA, R., OHTSUKA, T. and KOBAYASHI, T. (2007b). The Hes gene family: repressors and oscillators that orchestrate embryogenesis. Development 134 $1243-51$ 
KIDD, S. and LIEBER, T. (2002). Furin cleavage is not a requirement for Drosophila Notch function. Mech Dev 115: 41-51.

KLEIN, T. (2003). The tumour suppressor gene I(2)giant discs is required to restrict the activity of Notch to the dorsoventral boundary during Drosophila wing development. Dev Bio/255: 313-33.

KUO, C.T., MIRZADEH, Z., SORIANO-NAVARRO, M., RASIN, M., WANG, D., SHEN, J., SESTAN, N., GARCIA-VERDUGO, J., ALVAREZ-BUYLLA, A., JAN, L.Y. et al. (2006). Postnatal deletion of Numb/Numblike reveals repair and remodeling capacity in the subventricular neurogenic niche. Ce//127: 1253-64.

LE BORGNE, R. (2006). Regulation of Notch signalling by endocytosis and endosomal sorting. Curr Opin Cel/ Biol18: 213-22.

LEHMANN, R., JIMÉNEZ, F., DIETRICH, U. and CAMPOS-ORTEGA, J.A. (1983). On the phenotype and development of mutants of early neurogenesis in Drosophila melanogaster. Roux's Arch. Dev. Biol. 192: 62-74.

LEWIS, J. (1996). Neurogenic genes and vertebrate neurogenesis. Curr Opin Neurobio/6: 3-10.

LEWIS, J. (2003). Autoinhibition with transcriptional delay: a simple mechanism for the zebrafish somitogenesis oscillator. Curr Bio/13: 1398-408.

LI, H.S., WANG, D., SHEN, Q., SCHONEMANN, M.D., GORSKI, J.A., JONES, K.R., TEMPLE, S., JAN, L.Y. and JAN, Y.N. (2003). Inactivation of Numb and Numblike in embryonic dorsal forebrain impairs neurogenesis and disrupts cortical morphogenesis. Neuron 40: 1105-18.

LOGEAT, F., BESSIA, C., BROU, C., LEBAIL, O., JARRIAULT, S., SEIDAH, N.G. and ISRAEL, A. (1998). The Notch1 receptor is cleaved constitutively by a furinlike convertase. Proc Natl Acad Sci USA 95: 8108-12.

LOUVI, A. and ARTAVANIS-TSAKONAS, S. (2006). Notch signalling in vertebrate neural development. Nat Rev Neurosci 7: 93-102.

MASAMIZU, Y., OHTSUKA, T., TAKASHIMA, Y., NAGAHARA, H., TAKENAKA, Y., YOSHIKAWA, K., OKAMURA, H. and KAGEYAMA, R. (2006). Real-time imaging of the somite segmentation clock: revelation of unstable oscillators in the individual presomitic mesoderm cells. Proc Nat/ Acad Sci USA 103: 13138.

MATSUNO, K., DIEDERICH, R.J., GO, M.J., BLAUMUELLER, C.M. and ARTAVANIS-TSAKONAS, S. (1995). Deltex acts as a positive regulator of Notch signaling through interactions with the Notch ankyrin repeats. Development 121: 2633-44.

MCGILL, M.A. and MCGLADE, C.J. (2003). Mammalian numb proteins promote Notch1 receptor ubiquitination and degradation of the Notch1 intracellular domain. J Biol Chem 278: 23196-203.

MEIR, E., VON DASSOW, G., MUNRO, E. and ODELL, G.M. (2002). Robustness, flexibility, and the role of lateral inhibition in the neurogenic network. Curr Biol 12: 778-86.

MOBERG, K.H., SCHELBLE, S., BURDICK, S.K. and HARIHARAN, I.K. (2005). Mutations in erupted, the Drosophila ortholog of mammalian tumor susceptibility gene 101, elicit non-cell-autonomous overgrowth. Dev Ce//9: 699-710.

OKAJIMA, T. and IRVINE, K.D. (2002). Regulation of notch signaling by o-linked fucose. Cel/111: 893-904.

OKAJIMA, T., XU, A., LEI, L. and IRVINE, K.D. (2005). Chaperone activity of protein O-fucosyltransferase 1 promotes notch receptor folding. Science 307: 1599603.

PALMEIRIM, I., HENRIQUE, D., ISH-HOROWICZ, D. and POURQUIE, O. (1997). Avian hairy gene expression identifies a molecular clock linked to vertebrate segmentation and somitogenesis. Cel/91: 639-48.

PETERSEN, P.H., ZOU, K., HWANG, J.K., JAN, Y.N. and ZHONG, W. (2002). Progenitor cell maintenance requires numb and numblike during mouse neurogenesis. Nature 419: 929-34.

POULSON, D.F. (1937). Chromosomal Deficiencies and the Embryonic Development of Drosophila Melanogaster. Proc Nat/ Acad Sci USA 23: 133-7.

POULSON, D.F. (1945). Chromosomal Control of Embryogenesis in Drosophila. The America Naturalist 79: 340-363.

POURQUIE, O. (2003). The segmentation clock: converting embryonic time into spatial pattern. Science 301: 328-30.

REBEIZ, M., REEVES, N.L. and POSAKONY, J.W. (2002). SCORE: a computational approach to the identification of cis-regulatory modules and target genes in whole-genome sequence data. Site clustering over random expectation. Proc Natl Acad Sci USA 99: 9888-93.

SASAMURA, T., ISHIKAWA, H.O., SASAKI, N., HIGASHI, S., KANAI, M., NAKAO, S., AYUKAWA, T., AIGAKI, T., NODA, K., MIYOSHI, E. et al. (2007). The Ofucosyltransferase O-fut1 is an extracellular component that is essential for the constitutive endocytic trafficking of Notch in Drosophila. Development 134: 1347-56.

SASAMURA, T., SASAKI, N., MIYASHITA, F., NAKAO, S., ISHIKAWA, H.O., ITO, M., KITAGAWA, M., HARIGAYA, K., SPANA, E., BILDER, D. et al. (2003). neurotic, a novel maternal neurogenic gene, encodes an $O$-fucosyltransferase that is essential for Notch-Delta interactions. Development 130: 4785-95.

SCHWEISGUTH, F. (2004). Notch signaling activity. Curr Bio/14: R129-38.

SHAYE, D.D. and GREENWALD, I. (2002). Endocytosis-mediated downregulation of LIN-12/Notch upon Ras activation in Caenorhabditis elegans. Nature 420: 686-90.

SHAYE, D.D. and GREENWALD, I. (2005). LIN-12/Notch trafficking and regulation of DSL ligand activity during vulval induction in Caenorhabditis elegans. Development 132: 5081-92.

SHI, S. and STANLEY, P. (2003). Protein O-fucosyltransferase 1 is an essential component of Notch signaling pathways. Proc Nat/ Acad Sci USA 100: 5234-9.

STROM, A., CASTELLA, P., ROCKWOOD, J., WAGNER, J. and CAUDY, M. (1997). Mediation of NGF signaling by post-translational inhibition of HES-1, a basic helix-loop-helix repressor of neuronal differentiation. Genes Dev 11: 3168-81.

THOMPSON, B.J., MATHIEU, J., SUNG, H.H., LOESER, E., RORTH, P. and COHEN, S.M. (2005). Tumor suppressor properties of the ESCRT-II complex component Vps25 in Drosophila. Dev Cel/9: 711-20.

VACCARI, T. and BILDER, D. (2005). The Drosophila tumor suppressor vps25 prevents nonautonomous overproliferation by regulating notch trafficking. $\mathrm{Dev}$ Cel/9: 687-98.

VÄSSIN, H., VIELMETTER, J. and CAMPOS-ORTEGA, J.A. (1985). Genetic interactions in early neurogenesis of Drosophila melanogaster. J. Neurogenet 2: 291-308.

WENG, A.P., FERRANDO, A.A., LEE, W., MORRIS, J.P.T., SILVERMAN, L.B., SANCHEZ-IRIZARRY, C., BLACKLOW, S.C., LOOK, A.T. and ASTER, J.C. (2004). Activating mutations of NOTCH1 in human T cell acute lymphoblastic leukemia. Science 306: 269-71.

ZHONG, W., JIANG, M.M., SCHONEMANN, M.D., MENESES, J.J., PEDERSEN, R.A., JAN, L.Y. and JAN, Y.N. (2000). Mouse numb is an essential gene involved in cortical neurogenesis. Proc Natl Acad Sci USA 97: 6844-9. 


\section{Related, previously published Int. J. Dev. Biol. articles}

See our recent Special Issue Ear Development edited by Fernando Giraldez and Bernd Fritzsch at: http://www.ijdb.ehu.es/web/contents. php?vol=51\&issue=6-7

Xenopus glucose transporter 1 (xGLUT1) is required for gastrulation movement in Xenopus laevis Keiko Suzawa, Akira Yukita, Tadayoshi Hayata, Toshiyasu Goto, Hiroki Danno, Tatsuo Michiue, Ken W. Cho and Makoto Asashima

Int. J. Dev. Biol. (2007) 51: 183-190

Geometry and mechanics of teleost gastrulation and the formation of primary embryonic axes Elena M. Cherdantseva and Vladimir G. Cherdantsev

Int. J. Dev. Biol. (2006) 50: 157-168

Xenopus nodal related-1 is indispensable only for left-right axis determination Ryuji Toyoizumi, Tsuyoshi Ogasawara, Shigeo Takeuchi and Kazue Mogi

Int. J. Dev. Biol. (2005) 49: 923-938

cdx4/lacZ and cdx2/lacZ protein gradients formed by decay during gastrulation in the mouse

Stephen J. Gaunt, Deborah Drage and Richard C. Trubshaw

Int. J. Dev. Biol. (2005) 49: 901-908

Xantivin suppresses the activity of EGF-CFC genes to regulate nodal signaling

Kousuke Tanegashima, Yoshikazu Haramoto, Chika Yokota,Shuji Takahashi and Makoto Asashima

Int. J. Dev. Biol. (2004) 48: 275-283

Multiple interactions between maternally-activated signalling pathways control Xenopus nodal-related genes.

Maria Rex, Emma Hilton and Robert Old

Int. J. Dev. Biol. (2002) 46: 217-226

Goosecoid and cerberus-like do not interact during mouse embryogenesis. Ana C Borges, Sara Marques and José A Belo

Int. J. Dev. Biol. (2002) 46: 259-262

The BMP antagonists cerberus-like and noggin do not interact during mouse forebrain development.

A C Borges, S Marques and J A Belo

Int. J. Dev. Biol. (2001) 45: 441-444

Siamois cooperates with TGFbeta signals to induce the complete function of the Spemann-Mangold organizer.

M J Engleka and D S Kessler

Int. J. Dev. Biol. (2001) 45: 241-250

Nodal signaling and the zebrafish organizer.

A F Schier and W S Talbot

Int. J. Dev. Biol. (2001) 45: 289-297

Molecular mechanisms of cell-cell signaling by the Spemann-Mangold organizer.

E M De Robertis, O Wessely, M Oelgeschläger, B Brizuela, E Pera, J Larraín, J Abreu and D Bachiller

Int. J. Dev. Biol. (2001) 45: 189-197

Developmental biology of amphibians after Hans Spemann in Germany. H Grunz

Int. J. Dev. Biol. (2001) 45: 39-50

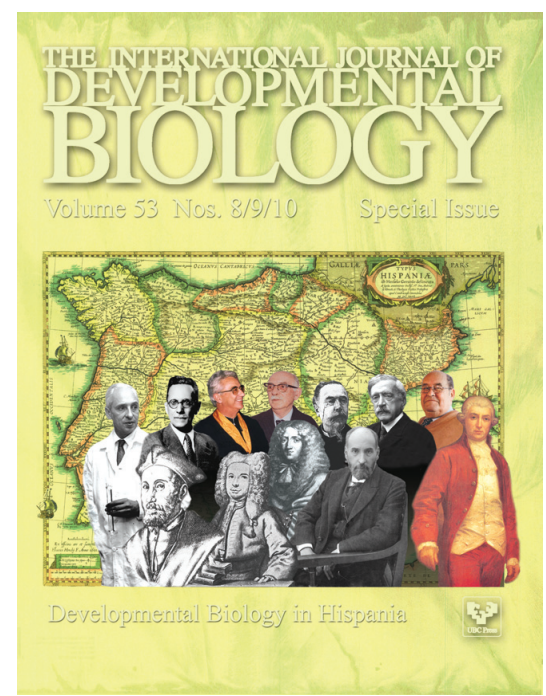

5 yr ISI Impact Factor $(2008)=3.271$
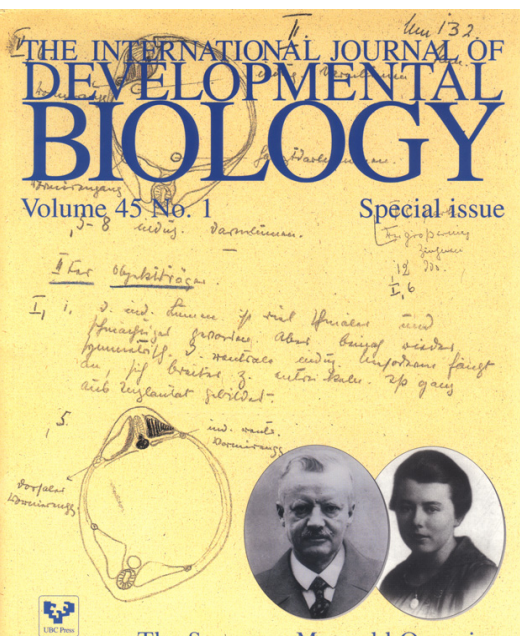

The Spemann-Mangold Organizer 